\title{
Using DNA Fingerprinting to Detect the Genetic Relationships in Acacia by Inter-Simple Sequence Repeat Markers
}

\author{
Arshad Naji Alhasnawi ${ }^{1 *}$, Amar Mousa Mandal and Haider Mahmooed Jasim ${ }^{1}$ \\ ${ }^{1}$ Department of Biology, College of Education for Pure Sciences, Al Muthanna University, Samawah, 66001, Iraq. \\ ${ }^{2}$ Science Department, Faculty of Basic Education, Al Muthanna University, Samawah, 66001, Iraq.
}

\begin{abstract}
The objective of this study was to complete the molecular evaluation of five Acacia species including first by determining the genetic diversity of the plants using the polymerase chain reaction (PCR)-based inter-simple sequence repeat (ISSR) method. This investigation was carried out to assess fingerprint and thus genetic variations among the Acacia species. The ISSR method was used to determine DNA fingerprints for Acacia spp. Eight primers were used, with all primers delivering amplification products. Our data show a total of 71 bands of 70 bp to 2,200 bp were amplified, of which 0.77 demonstrated an average polymorphism information content per primer. Among the eight primers tested, the mean annealing temperature was $48^{\circ} \mathrm{C}$ and average polymorphism information content was between 0.36 and 0.84. The ISSR primers for the five species of Acacia showed four main groups, with a higher level of similarity between these species. These results indicated ISSR markers provide an efficient alternate for identification via DNA fingerprinting of the genetic relationships in Acacia. PCR-based ISSR represents a powerful method that can provide practical information for the development of molecular markers, molecular cytogenetic techniques, and DNA Fingerprinting for application in an Acacia spp breeding program.
\end{abstract}

Keywords: DNA, Molecular Markers, ISSR Primer, Genetic Diversity, Molecular Relationships, Acacia spp.

\footnotetext{
*Correspondence: arshad@mu.edu.iq

(Received: 28 January 2019; accepted: 09 March 2019)

Abbreviations: (ISSR) Inter-Simple Sequence Repeats, (PIC) Polymorphism information content.

Citation: Arshad Naji Alhasnawi, Amar Mousa Mandal and Haider Mahmooed Jasim, Using DNA Fingerprinting to Detect the Genetic Relationships in Acacia by Inter-Simple Sequence Repeat Markers, J Pure Appl Microbiol., 2019; 13(1):281-288 doi: 10.22207/JPAM.13.1.30

(C) The Author(s) 2019. Open Access. This article is distributed under the terms of the Creative Commons Attribution 4.0 International License which permits unrestricted use, sharing, distribution, and reproduction in any medium, provided you give appropriate credit to the original author(s) and the source, provide a link to the Creative Commons license, and indicate if changes were made.
} 


\section{INTRODUCTION}

Acacia spp. plants (family: Mimosaceae) number more than 1,500 species and have been planted in more than 80 countries around the world. To date, there are more than two million hectares of land-care plantings in South and Central America, Africa, Asia, and Australia (Old et al., 2002), with the plants used for their medicinal and health-promoting properties, including the leaves in the treatment of skin disease and asthma disease and as food (Thambiraj and Paulsamy, 2012). Acaciais also planted to yield pulp for paper and as a source of wood (Choung, 2010).

DNA fingerprinting has been widely beneficial in detecting genetic variation within breeding populations in order to differentiate accessions and positively identify species and cultivars that might be difficult to characterize because of indistinct traits or which have similar morphological characteristics. It has also been used to identify plants containing genes of interest. Importantly, a number of molecular technical methods are being used to create DNA fingerprinting assessments and each of these has certain weaknesses and strengths (Saunders et al., 2014). Tracing the unknown origin of species or cultivars has been another valuable contribution of DNA fingerprinting to germplasm characterization. For example Regner et al. (2001) utilized microsatellite, inter-simplesequence repeat (ISSR), random Amplified Polymorphic DNA (RAPD), and amplifed fragment length polymorphism (AFLP) techniques to investigate 1,200 vines (Vitis species) and were able to describe the history of many cultivars still in use, going back to the Middle Ages. Separately, using only microsatellites, Laigret and Luro (1995) effectively studied the origin of different Citrus species and their relationships.

ISSR is a polymerase chain reaction (PCR)-created method that employs moderately short primers that line microsatellite regions (Taylor and Barker 2012). The application of the ISSR method is beneficial, as molecular markers have roles to present to enhance a population genotype classification, in addition to providing essential baseline information for the gene pool management and breeding strategies of Acacia(Josiah et al., 2008). The level of genetic variation in seed Acacia is important to plantation forests, as high levels will enhance plant tolerance to climate change, diseases, or pests (Shanthi and Priya, 2015).

Thus, ISSR amplifications were applied to evaluate genetic diversity among these plants and to investigate microsatellite motif frequency in the plants (Alhasnawi et al. 2015). The ISSR investigation provided insights into the levels, frequency, and organization of polymorphism of deferent simple-sequence repeat (SSR). The ISSR amplification findings were utilized to group plant genotypes through cluster analysis. As a result, ISSR amplification proved to be a valuable technique to rapidly identify cultivars and determine genetic variability among plant varieties. This effective genetic fingerprinting method could be beneficial for describing the large numbers of plant accessions held in international and national germplasm centres (Blair et al., 1999). The ISSR technique has been previously successfully utilized in studies on the genetic variation of Acacia(Taylor and Barker, 2012). The usefulness of incorporating main DNA markers-for example, ISSR markersto evaluate germplasm diversity and characterize interspecific relationships in the Acacia auriculiformis population in the seedling seed orchard has also been identified (Shanthi and Priya 2015). The objectives of the present study were to design and optimize ISSR primers and use DNA finger-printing for the assessment of genetic relationships in species of Acacia by using ISSR molecular markers.

\section{MATERIALS AND METHODS}

Five species of Acacia spp. (Acacia accutifolia, Acacia arabica, Acacia salicina, Acacia saligna, and Acacia logifolia) were used in this research in the process of DNA fingerprinting to determine genetic relationships by using ISSR markers.

\section{DNA isolation}

The genomic DNA Acacia genotypes were isolated using EasyPrep ${ }^{\mathrm{TM}}$ Plant Genomic DNA Miniprep Kit (50), Cat No. GD02-01, Bioland Scientific LLC, USA.

\section{Polymerase chain reaction}

The temperature profile used was as follows: initial denaturation of DNA strand at $94^{\circ} \mathrm{C}$ for 30 seconds, denaturation at $94^{\circ} \mathrm{C}$ for 30 seconds, annealing of primers at $48^{\circ} \mathrm{C}$ to $51^{\circ} \mathrm{C}$ (gradient temperature) for 60 seconds, extension 
at $68^{\circ} \mathrm{C}$ for one minute/kb for 30 cycles; final extension at $68^{\circ} \mathrm{C}$ for five minutes; and then hold at $5^{\circ} \mathrm{C}$. The optimization for PCR reagents was completed employing an optimized primer combination and annealing temperature. The ISSR patterns were analysed in volumes of $25 \mu \mathrm{L}$ by using OneTaq ${ }^{\circledR}$ Quick-Load $^{\circledR}$ 2X Master Mix with Standard Buffer (M0486S; BioLabs, UK).

Primer selection and polymerase chain reaction optimization

The ISSR sequences of design primers with restricted sites on primer sequence 5-3 for design primers by alpha DNA were determined. Details of the ISSR primer sequences can be found in Table 1. The optimization of PCR involved the gradient annealing temperature composed by eight combinations of ISSR designed according to standard PCR techniques. Four gradient temperatures were utilized, including $48^{\circ} \mathrm{C}$, $49^{\circ} \mathrm{C}, 50^{\circ} \mathrm{C}$, and $51^{\circ} \mathrm{C}$. Thirty PCR cycles were completed in a thermal cycler (T100 ${ }^{\text {TM }}$; Bio-Rad Laboratories, Hercules, CA, USA). PCR amplification reactions were analysed by $1.5 \%(\mathrm{w} / \mathrm{v})$ agarose gel electrophoresis at $75 \mathrm{~V}$.

\section{Data analysis}

ISSR-PCR bands were recorded as marker, absent (0), or present (1) at each band position for

Table 1. Details of ISSR primer and sequence

\begin{tabular}{llll}
\hline $\begin{array}{l}\text { ISSR } \\
\text { Primer }\end{array}$ & Primer Sequence 5' - 3' & Length \\
\hline ISSR 1 & $(\mathrm{AC})_{8} \mathrm{G}$ & ACACACACACACACACG & 17 mers \\
ISSR 2 & $(\mathrm{AG})_{8} \mathrm{~T}$ & AGAGAGAGAGAGAGAGT & 17 mers \\
ISSR 3 & $(\mathrm{TG})_{8} \mathrm{C}$ & TGTGTGTGTGTGTGTGC & 17 mers \\
ISSR 4 & $\mathrm{A}(\mathrm{CAG})_{5}$ & ACAGCAGCAGCAGCAG & 16 mers \\
ISSR 5 & $(\mathrm{GT})_{8} \mathrm{C}$ & GTGTGTGTGTTGTGTC & 17 mers \\
ISSR 6 & $\mathrm{G} \mathrm{(CA})_{8}$ & GCACACACACACACACA & 17 mers \\
ISSR 7 & $(\mathrm{GT})_{8} \mathrm{C}$ & GTGTGTGTGTGGTGTC & 17 mers \\
ISSR 8 & $(\mathrm{GA})_{8} \mathrm{G}$ & GAGAGAGAGAGAGAGAG & 17 mers \\
\hline
\end{tabular}

the four species for every ISSR primer. Annealing temperature; ratio of amplified bands; and A, T, C, $G$, and $G+C$ content for ISSR markers were noted. The ISSR scores were used to create a data matrix to investigate genetic variation among the five species using the CLC Sequence Viewer program version 6.8.1 for Windows. The total number of bands, polymorphism information content (PIC), approximate fragment size range (bp), average frequency of alleles present, average frequency of alleles absent, and average PIC per ISSR primer for five species were determined.

\section{RESULTS}

In the present investigation, genetic variations among the Acacia spp. were studied by using several ISSR markers via identifying the DNA fingerprints shown in Table 1. The ISSR markers were 16 to 17 mers bases long and the annealing temperatures were optimized. The genomic DNA of the five species of accessions was amplified using eight ISSR primers and yielded a total of 135 mers bases, with an average of 16.88 mers bases for the eight ISSR primers (Table 2). The mean percentage of bases of adenine (A) was $28.22 \%$, of cytosine (C) was $17.88 \%$, of guanine (G) was $35.52 \%$, of thymine (T) was $18.38 \%$, of adenine (A) + thymine (T) was $46.60 \%$, and of cytosine (C) + guanine (G) was $53.40 \%$, respectively, for the eight ISSR primers shown in Table 2. Optimum components and markers choices led to four annealing temperature to choose from ranging from $48^{\circ} \mathrm{C}$ to $51^{\circ} \mathrm{C}$, whichwere screened for the amplification of Acacia spp. Clear bands were observed at $48^{\circ} \mathrm{C}$ for all primers (Fig. 1).

Our investigation revealed that eight ISSR specific markers were screened for the amplification of Acacia for the optimum ISSR primer annealing temperature. Nonetheless, for the optimization of markers, we used DNA of one Acacia spp. The selected optimizing annealing temperatures for PCR markers were determined based on the great clear bands created (Table 1).

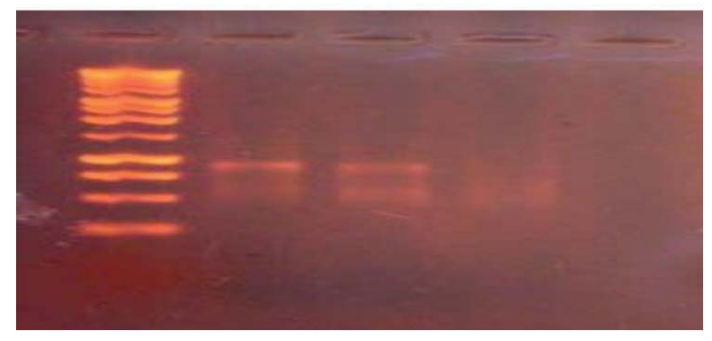

Fig. 1. Gel images generated of DNA obtained by ISSR 3 Lane M: DNA Marker $100 \mathrm{bp}$

Lane 1: annealing temperature $48^{\circ} \mathrm{C}$

Lane 2: annealing temperature $49^{\circ} \mathrm{C}$

Lane 3: annealing temperature $50^{\circ} \mathrm{C}$

Lane 4: annealing temperature $51^{\circ} \mathrm{C}$ 
Table 2. The percentage of nucleotide sequences, used for molecular characterization

\begin{tabular}{|c|c|c|c|c|c|c|c|c|}
\hline \multirow[b]{2}{*}{$\begin{array}{l}\text { ISSR } \\
\text { Primer }\end{array}$} & \multirow{2}{*}{$\begin{array}{c}\text { Primer } \\
\text { sequence } \\
\left(5^{\prime}-3^{\prime}\right)\end{array}$} & \multirow[b]{2}{*}{$\begin{array}{c}\text { Length } \\
\text { mers }\end{array}$} & \multicolumn{5}{|c|}{ The percentage of } & \multirow[b]{2}{*}{$\overline{C+G}$} \\
\hline & & & $A$ & $\mathrm{C}$ & G & $\mathrm{T}$ & $A+T$ & \\
\hline ISSR 1 & $(\mathrm{AC})_{8} \mathrm{G}$ & 17 & 47.06 & 47.06 & 5.88 & 0.00 & 47.06 & 52.94 \\
\hline ISSR 2 & $(A G)_{8}^{8} T$ & 17 & 47.06 & 0.00 & 47.06 & 5.88 & 52.94 & 47.06 \\
\hline ISSR 3 & $(\mathrm{TG})_{8}^{8} \mathrm{C}$ & 17 & 0.00 & 5.88 & 47.06 & 47.06 & 47.06 & 52.94 \\
\hline ISSR 4 & $A(C A G)_{5}$ & 16 & 37.50 & 31.25 & 31.25 & 0.00 & 37.50 & 62.50 \\
\hline ISSR 5 & $(\mathrm{GT})_{8} \mathrm{C}^{3}$ & 17 & 0.00 & 5.88 & 47.06 & 47.06 & 47.06 & 52.94 \\
\hline ISSR 6 & $\mathrm{G}(\mathrm{CA})_{8}$ & 17 & 47.06 & 47.06 & 5.88 & 0.00 & 47.06 & 52.94 \\
\hline ISSR 7 & $(\mathrm{GT})_{8} \mathrm{C}$ & 17 & 0.00 & 5.88 & 47.06 & 47.06 & 47.06 & 52.94 \\
\hline ISSR 8 & $(G A)_{8}^{8} G$ & 17 & 47.06 & 0.00 & 52.94 & 0.00 & 47.06 & 52.94 \\
\hline Total & & 135 & 225.7 & 143.0 & 284.2 & 147.1 & 372.8 & 427.2 \\
\hline Mine & & 16.88 & 28.22 & 17.88 & 35.52 & 18.38 & 46.60 & 53.40 \\
\hline
\end{tabular}

The results in Figure 1 illustrate that there was an optimal annealing temperature for select markers. In this phase of the present investigation, ISSR primers gave positive amplification temperatures. We selected the well visible and clear bands and considered them in a further assessment. As a result, eight markers were found to produce strong amplifications that were used in genetic investigation for the best annealing temperature for ISSR primers (Table 3).

Results showed that, in the ISSR eight primers, the ideal annealing temperature was $48^{\circ} \mathrm{C}$ (Table 3). The results presented in Table 3 indicate the average polymorphism information content as 0.84 , the average frequency of alleles that were absent was 2.00, and the average frequency of alleles that were present was 0.650 . We observed that, for the ISSR2 primer, the average polymorphism information content was 0.36 , the average frequency of alleles that were absent was 1.18 , and the average frequency of alleles that were present was 0.50 . In the ISSR3 primer, the average polymorphism information content was 0.84 , the average frequency of alleles that were absent was 1.63, and the average frequency of alleles that were present was 0.45 . for the ISSR4 primer, the average polymorphism information content was 0.64 , the average frequency of alleles that were absent was 1.75 , and the average frequency of alleles that were present was 0.60 .

Table 3. Data on annealing temperature $\left({ }^{\circ} \mathrm{C}\right)$, average pic per primer, average frequency of alleles absent, and average frequency of alleles present for ISSR markers

\begin{tabular}{|c|c|c|c|c|c|c|c|c|}
\hline & $\begin{array}{c}\text { ISSR } \\
1\end{array}$ & $\begin{array}{c}\text { ISSR } \\
2\end{array}$ & $\begin{array}{c}\text { ISSR } \\
3\end{array}$ & $\begin{array}{c}\text { ISSR } \\
4\end{array}$ & $\begin{array}{c}\text { ISSR } \\
5\end{array}$ & $\begin{array}{c}\text { ISSR } \\
6\end{array}$ & $\begin{array}{c}\text { ISSR } \\
7\end{array}$ & $\begin{array}{c}\text { ISSR } \\
8\end{array}$ \\
\hline $\begin{array}{l}\text { Annealing } \\
\text { Temperature } \\
\left({ }^{\circ} \mathrm{C}\right)\end{array}$ & $48^{\circ} \mathrm{C}$ & $48^{\circ} \mathrm{C}$ & $48^{\circ} \mathrm{C}$ & $48^{\circ} \mathrm{C}$ & $48^{\circ} \mathrm{C}$ & $48^{\circ} \mathrm{C}$ & $48^{\circ} \mathrm{C}$ & $48^{\circ} \mathrm{C}$ \\
\hline $\begin{array}{l}\text { Average } \\
\text { PIC per } \\
\text { primer }\end{array}$ & 0.84 & 0.36 & 0.84 & 0.64 & 0.84 & 0.96 & 0.84 & 0.84 \\
\hline $\begin{array}{l}\text { Average } \\
\text { Frequency } \\
\text { of alleles } \\
\text { absent }\end{array}$ & 2.00 & 1.19 & 1.63 & 1.75 & 1.06 & 1.00 & 1.69 & 1.44 \\
\hline $\begin{array}{l}\text { Average } \\
\text { Frequency of } \\
\text { alleles } \\
\text { present }\end{array}$ & 0.65 & 0.50 & 0.45 & 0.60 & 0.40 & 0.20 & 0.40 & 0.35 \\
\hline
\end{tabular}



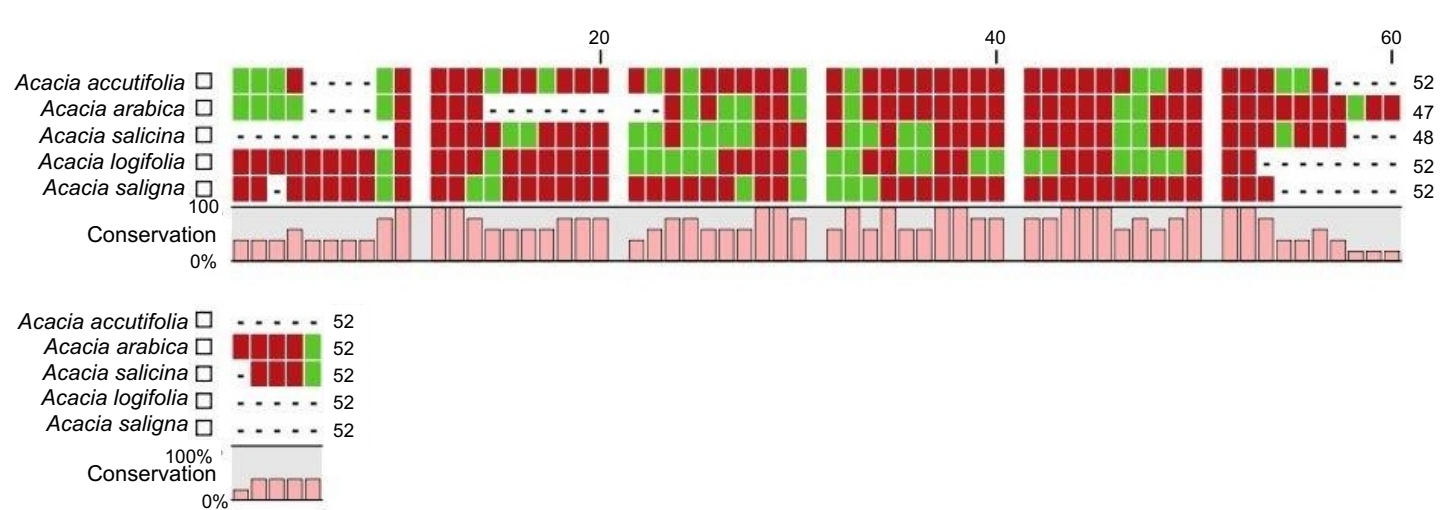

Fig. 2. Alignment of population structure of five Acacia spp.

Considering the results of the ISSR5 primer, the average polymorphism information content was 0.84 , the average frequency of alleles that were absent was 1.03, and the average frequency of alleles that were present was 0.400 . In the case of the ISSR6 primer, the average polymorphism information content was 0.69 , the average frequency of alleles that were absent was 1.00, and the average frequency of alleles that were present was 0.20 . For the ISSR7 primer, the average polymorphism information content was 0.84 , the average frequency of alleles that were absent was 1.69 and the average frequency of alleles that were present was 0.40. Lastly, for the ISSR8 primer, the average polymorphism information content was 0.84 , the average frequency of alleles that were absent was 1.75 , and the average frequency of alleles that were present was 0.35 . The typical fingerprints obtained for Acacia spp. revealed that the eight ISSR primer products are of different sizes, a finding which was easily obtained on the visualized sequencing gel by way of gel electrophoresis of DNA. The eight primers produced new bands that were reproducible and clear.

Separately, the results in Table 4 reveal that the number of amplified bands produced by the used ISSR1 primer ranged from one to five bands, while the amplicon size varied from $70 \mathrm{bp}$ to $2,000 \mathrm{bp}$ in all of the Acacia spp. The number of amplified bands produced by the used ISSR2 primer ranged from one to two bands and the amplicon size varied from $100 \mathrm{bp} 800 \mathrm{bp}$ in all of the Acacia spp. Additionally, the number of amplified bands produced by the used ISSR3 primer ranged from one to four bands and the amplicon size varied from $100 \mathrm{bp}$ to $2,000 \mathrm{bp}$ in all of the Acacia spp., except Acacia saligna did not show any bands. The number of amplified bands produced by the used ISSR4 primer ranged from one to four bands and the amplicon size varied from 100 bp to 2,200 bp in all of the Acacia spp, except Acacia arabica did not show any bands. The number of amplified bands produced by the used ISSR5 primer ranged from two to three bands and the amplicon size varied from $300 \mathrm{bp}$ to 1,700
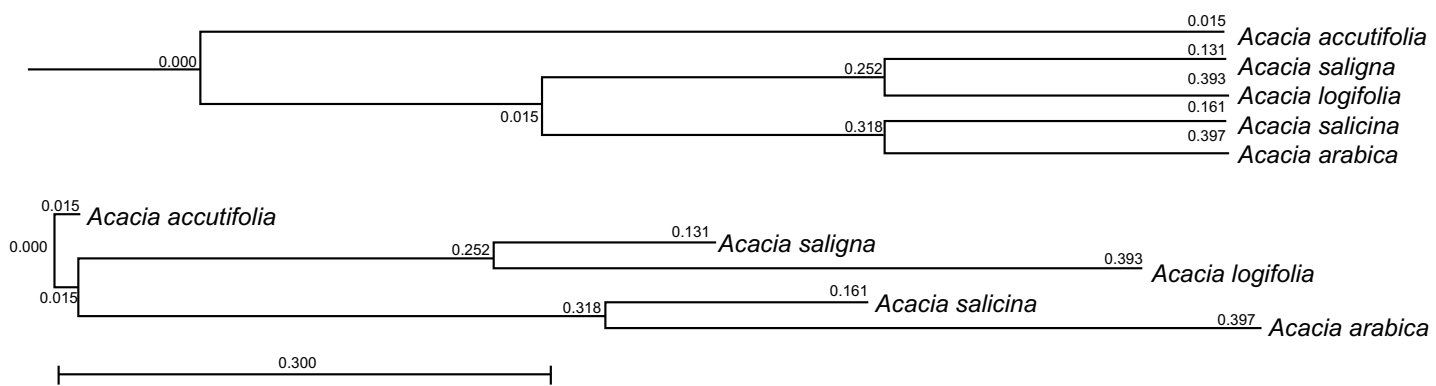

Fig. 3. Hierarchical analysis showing genetic relationship among the of five Acacia spp. based on data generated using 8 ISSR primers 
Table 4. Characteristics of total No. of bands, PIC, fragment size (bp), and total bands for ISSR markers amplification in Acacia spp.

\begin{tabular}{|c|c|c|c|c|c|c|c|c|c|}
\hline \multicolumn{2}{|l|}{ Species } & \multirow{2}{*}{$\begin{array}{l}\text { ISSR } 1 \\
4\end{array}$} & \multirow{2}{*}{$\begin{array}{l}\text { ISSR } 2 \\
2\end{array}$} & \multirow{2}{*}{$\frac{\text { ISSR } 3}{3}$} & \multirow{2}{*}{$\frac{\text { ISSR } 4}{2}$} & \multirow{2}{*}{$\begin{array}{l}\text { ISSR } 5 \\
-\end{array}$} & \multirow{2}{*}{$\begin{array}{l}\text { ISSR } 6 \\
-\end{array}$} & \multirow{2}{*}{$\begin{array}{l}\text { ISSR } 7 \\
2\end{array}$} & \multirow{2}{*}{$\begin{array}{l}\text { ISSR } 8 \\
2\end{array}$} \\
\hline A. accutifolia & $\begin{array}{l}\text { Total No. } \\
\text { of bands }\end{array}$ & & & & & & & & \\
\hline & $\mathrm{PIC}$ & 0.44 & 0.40 & 0.29 & 0.25 & - & - & 0.29 & 0.29 \\
\hline & $\begin{array}{l}\text { Fragment } \\
\text { size (bp) }\end{array}$ & $\begin{array}{l}1000- \\
2000\end{array}$ & $300-800$ & $300-750$ & $300-500$ & - & - & $450-550$ & $\begin{array}{l}300- \\
500\end{array}$ \\
\hline \multirow[t]{3}{*}{ A. arabica } & Total No. & $\begin{array}{l}5 \\
\text { of bands }\end{array}$ & 2 & 2 & - & 2 & - & 1 & - \\
\hline & $\mathrm{PIC}$ & 0.56 & 0.60 & 0.29 & - & 0.40 & - & 0.14 & - \\
\hline & $\begin{array}{l}\text { Fragment } \\
\text { size (bp) }\end{array}$ & $\begin{array}{l}1000- \\
2000\end{array}$ & $300-750$ & $400-850$ & - & $300-500$ & - & $100-100$ & - \\
\hline \multirow[t]{3}{*}{ A. salicina } & $\begin{array}{l}\text { Total No. } \\
\text { of bands }\end{array}$ & 2 & 2 & 4 & 4 & - & 2 & 1 & - \\
\hline & $\mathrm{PIC}$ & 0.22 & 0.40 & 0.57 & 0.50 & - & 0.50 & 0.14 & - \\
\hline & $\begin{array}{l}\text { Fragment } \\
\text { size (bp) }\end{array}$ & $400-600$ & $300-500$ & $\begin{array}{l}500- \\
2000\end{array}$ & $\begin{array}{l}400- \\
2000\end{array}$ & - & $300-500$ & $100-100$ & - \\
\hline \multirow[t]{3}{*}{ A. saligna } & $\begin{array}{l}\text { Total No. } \\
\text { of bands }\end{array}$ & 1 & 2 & - & 2 & 3 & - & - & 3 \\
\hline & $\mathrm{PIC}$ & 0.11 & 0.40 & - & 0.25 & 0.60 & - & - & 0.43 \\
\hline & $\begin{array}{l}\text { Fragment } \\
\text { size (bp) }\end{array}$ & $100-100$ & $300-500$ & - & $100-500$ & $\begin{array}{l}750- \\
1700\end{array}$ & - & - & $\begin{array}{l}750- \\
1700\end{array}$ \\
\hline \multirow[t]{3}{*}{ A. logifolia } & $\begin{array}{l}\text { Total No. } \\
\text { of bands }\end{array}$ & 1 & 1 & 1 & 4 & 3 & 2 & 4 & 2 \\
\hline & $\mathrm{PIC}$ & 0.11 & 0.20 & 0.14 & 0.50 & 0.60 & 0.50 & 0.57 & 0.29 \\
\hline & $\begin{array}{l}\text { Fragment } \\
\text { size (bp) }\end{array}$ & $70-70$ & $100-100$ & $100-100$ & $\begin{array}{l}800- \\
2200\end{array}$ & $\begin{array}{l}750- \\
1700\end{array}$ & $2-2200$ & $\begin{array}{l}1500- \\
2200\end{array}$ & $\begin{array}{l}1000- \\
2000\end{array}$ \\
\hline \multicolumn{2}{|c|}{ Total bands $=71$} & 13 & 9 & 10 & 12 & 8 & 4 & 8 & 7 \\
\hline
\end{tabular}

bp in Acacia arabica, Acacia saligna, and Acacia logifolia. The number of amplified bands produced by the used ISSR6 primer was two bands and the amplicon size varied from $300 \mathrm{bp}$ to $2,200 \mathrm{bp}$ in Acacia salicina and Acacia logifolia. The number of amplified bands produced by the used ISSR7 primer ranged from one to four bands and the amplicon size varied from $100 \mathrm{bp}$ to $2,200 \mathrm{bp}$ in all of the Acacia spp., except Acacia saligna did not show any bands. Lastly, the number of amplified bands produced by the used ISSR8 primer ranged from two to three bands and the amplicons siz varied from $300 \mathrm{bp}$ to 2,000 bp in Acacia accutifolia, Acacia saligna, and Acacia logifolia.

The genetic diversity of the five Acacia spp. in this study was assessed with eight ISSR primers (Fig. 2 and 3). ISSR primers for the five species of Acacia displayed four main groups: group 1 includes Acacia saligna and Acacia logifolia, group 2 contains Acacia salicina and Acacia arabica, group 3 combines group 1 and group 2, and group 4 includes Acacia accutifolia and group 3). The diagram in Figure 3 reveals that the species similarity coefficient ranged from 0.252 (Acacia saligna / Acacia logifolia), 0.318 (Acacia salicina / Acacia arabica), and 0.015 (group 1 / group 2) to 0.000 (Acacia accutifolia / group 3). The species Acacia accutifolia and group 3showed more similarity than did the other species. The species Acacia arabica and Acacia logifolia showed more dissimilarity distance as compared with the rest of the Acacia species (Figure 3).

\section{DISCUSSION}

Optimal primer annealing temperatures for a specific PCR amplification are reliant on the base composition, nucleotide sequence, length, and concentration of the primers. Lower temperatures favour short fragment amplification, while higher temperature amplifications of large fragments are preferred (Mohamad et al., 2017). The present results agree with those found for polymorphism obtained using anchored $(G A) n$ and (AG)n ISSR primers, reflecting the taxonomic and conventional genetic correlations of a large set of plant germplasms (Sarla et al., 
2005). This was also supported by the study of Nazrul and Yin-Bing (2010), who identified good amplification products from ISSR primers based on (CT)n and (GA)n repeats. However, the primers with di-nucleotides motifs (AG)n, (CT)n, and (GA) $\mathrm{n}$ that lead to the induction of a higher level of polymorphism in plants include cumin, wheat, and wheat (Sheikhehpour et al., 2014).

Existing genetics technologies include directly sampling the DNA structure of the genomes, which can provide more accurate estimates of the true differences and similarities between genomes. The accuracy of genetic relationship evaluations based on molecular markers depends on the number and location(s) of the molecular markers utilized (Davierwala et al., 2000).

The productivity of ISSR markers can also be estimated by parameters, such as polymorphic information content. Molecular marker parameters like PIC application can be used for assessing the use potential of ISSR markers. Therefore, the present results are in agreement with the idea that the average value of PIC was 0.26 per ISSR primer. Comparing the average PIC value of each locus with the frequency of polymorphic bands at each locus showed that a larger number of polymorphic bands was related with reduced values of PIC (Grativol et al., 2011).

This lack of agreement underlines when the rank relationships are tested and raises a note of caution in terms of some of the applied molecular markers tools, particularly with regard to the identification of very similar accessions or duplicates (Virk et al., 2000).

The results of the current research indicate that a high level of polymorphism exists among Acacia species by using ISSR markers, suggesting the high efficiency and suitability of these ISSR markers to show the genetic differences of Acacia species. The use of a molecular technique could provide significant information about genetic polymorphism, elucidate inter-population genetic variations, and support the improvement and development of plant populations (Sheikhehpour et al., 2014). The present results are consistent with previous findings suggesting that ISSR tools are highly polymorphic fingerprints, reproducible, very reliable, and complete (Nazrul and Yin-Bing, 2010). ISSR primers are a powerful technique for producing a fingerprinting key and have the potential to identify species-specific ISSR markers for plants (Pharmawati et al. 2005). It was also supported that ISSR markers are reliable and efficient for the valuation of genetic diversity among grape species (Dhane et al. 2006).

\section{CONCLUSION}

DNA fingerprints as markers are a successful and powerful technique for plant breeding. In these experiments, ISSR markers represent a powerful tool in genetic research for DNA fingerprinting and have the potential to identify Acacia species. The complementary use of molecular markers, molecular cytogenetic techniques, and fingerprinting could enable a more accurate characterisation and evaluation of different Acacia species. This investigation indicates that land races exhibit very distinct identities and can be beneficial in generating mapping populations,genetic relationships, and breeding programs.

\section{ACKNOWLEDGMENT}

The research presented in this paper was supported by the Department of Biology, College of Education for Pure Sciences, and Science Department, Faculty of Basic Education, Al Muthanna University.

\section{CONFLICT OF INTERESTS}

The authors declare that there are no conflicts of interest.

\section{REFERENCES}

1. Alhasnawi AN, Kadhimi AA, Isahak A, Mohamed A, Doni F, Yusoff WM, Che Radziah Z. Application of inter simple sequence repeat (ISSR) for detecting genetic analysis in rice (Oryza sativa L.). J Pure Appl Microbiol, 2015; 9(2): 1091-1101.

2. Blair MW, Panaud O, McCouch SR. Inter-simple sequence repeat (ISSR) amplification for analysis of microsatellite motif frequency and finger-printing in rice (Oryza sativa L.). TAG Theoretical and Applied Genetics, 1999; 98: 780-792.

3. Choung MG.Determination of sucrose content in soybean using near-infrared reflectance spectro-scopy. J Appl Biolog Chem, 2010; 53: 578-584.

4. Davierwala AP, Chowdari K V, Kumar S, Reddy ARK, Ranjekar PK, Gupta VS.Use of three different marker systems to estimate genetic diversity of Indian elite rice varieties. Genetica 2000; 108: 269-284.

5. Dhane M, Tamhankar SA, Patil SG, Karibasappa GS, Rao 
VS. Assessment of genetic diversity and relationships among some grape varieties using ISSR markers. Journal of Applied Horticulture, 2006; 8: 50-52.

6. Grativol C, Lira-Medeiros CF, Hemerly AS, Ferreira PCG. High efficiency and reliability of inter-simple sequence repeats (ISSR) markers for evaluation of genetic diversity in Brazilian cultivated Jatropha curcas L. accessions. Molecular biology reports, 2011; 38: 4245-4256.

7. Josiah CC, George DO, Eleazar OM, Nyamu WF. Genetic diversity in Kenyan populations of Acacia Genetic diversity in Kenyan populations markers. African Journal of Biotechnology 2008; 7: 2333-2340.

8. Laigret F, Luro F. Preparation of high molecular weight genomic DNA from nuclei of woody plants. Bio. Techniques, 1995; 19 :388-392.

9. Mohamad A, Alhasnawi AN, Kadhimi AA, et al. DNA Isolation and Optimization of ISSR-PCR Reaction System in Oryza sativa L. International Journal on Advanced Science, Engineering and Information Technology, 2017; 7: 2088-5334.

10. Nazrul MI, Yin-Bing B. ISSR as New Markers for Identification of Homokaryotic Protoclones of Agaricus bisporus. Curr Microbiol., 2010; 60: 92-98.

11. Old KM, Vercoe TK, Floyd RB, Wingfield MJ, Roux J, Neser S. Acacia spp. FAO, Group on International Agricultural Research (CIGAR), 2002; 20: 1-48.

12. Pharmawati M, Yan G, Finnegan PM. Molecular variation and fingerprinting of Leucadendron cultivars (Proteaceae) by ISSR markers. Annals of Botany, 2005; 95: 1163-1170.
13. Regner F, Stadlbauer A, Eisenheld C. Molecular markers for genotyping grapevine and for identifying clones of traditional varieties. Acta Horticulturae, 2001; 546: 331-341.

14. Sarla N, Neeraja CN, Siddiq EA. Use of anchored (AG)n and (GA)n primers to assess genetic diversity of Indian landraces and varieties of rice. Current Science, 2005; 89: 1371-1381.

15. Saunders JA, Mischke S, Hemeida AA. The use of AFLP techniques for DNA fingerprinting in plants. Beckman Coulter, Inc., 2014; 1-8.

16. Shanthi A, Priya G. ISSR Marker analysis of acacia auriculiformis in first generation orchard populations. International J Sci Res, 2015; 4: 57-59.

17. Sheikhehpour S, Bahraminejad S, Cheghamirza K. Morphological and molecular genetic variations of oat genotypes grown in Kermanshah, Iran. Molecular Biology Reports, 2014; 41: 4023-4030.

18. Taylor CL, Barker NP. Species limits in vachellia (Acacia) karroo (Mimosoideae: Leguminoseae): Evidence from automated ISSR DNA fingerprinting. South African Journal of Botany, 2012; 83: 36-43.

19. Thambiraj J, Paulsamy S. Rapid in vitro multiplication of the ethnomedicinal shrub, Acacia caesia (L.) Willd. (Mimosaceae) from leaf explants. Asian Pacific Journal of Tropical Biomedicine, 2012; 2: S618-S622.

20. Virk PS, Zhu J, Newbury HJ, Bryan GJ, Jackson MT, FordLloyd BV. Effectiveness of different classes of molecular marker for classifying and revealing variation in rice (Oryza sativa) germplasm. Euphytica, 2000; 112: 275-284. 